\title{
A rare cause of acute severe hyponatraemia secondary to the syndrome of inappropriate anti- diuretic hormone (SIADH) secretion
}

Dr G. Wordsworth, Dr F. Hasan, Dr V. Parfitt, Dr F. Chau, Dr L. Cheyne, Dr K. Lonnen, Dr D. Tatovic, Dr A. Johnson

Department of Diabetes and Endocrinology, North Bristol NHS Trust, Bristol

\section{Introduction}

Hyponatremia is the commonest electrolyte abnormality presenting to Medical Admissions and when acute, severe and symptomatic, is associated with high mortality. The syndrome of inappropriate antidiuretic hormone secretion (SIADH) is the most common underlying disorder in hospitalised patients with euvolaemic hyponatraemia and is a complication of many clinical conditions and drug therapies.

We discuss the cases of two patients presenting with acute severe hyponatraemia secondary to SIADH, admitted to the same hospital within a 2-week period.

The number of possible causes of SIADH is extensive and maybe difficult to determine despite thorough investigation. We present the chronological events including clinical history and biochemical results in these patients which highlight the importance of considering rarer causes for unexplained hyponatraemia in those with additional symptoms suggestive of underlying pathology

\section{Background to cases}

\section{Patient $\mathbf{1 - 5 4}$ year old female}

No significant past medical history, no regular medication Presented $18^{\text {th }}$ May:

- $\quad$ Severe abdominal pain

- Hypertension

- $\quad$ Serum sodium $132 \mathrm{mmol} / \mathrm{L}$

Deteriorated $21^{\text {st }}$ May:

- $\quad$ Serum sodium $123 \mathrm{mmol} / \mathrm{L}$

- $\quad$ Seizure and 2222 call - transferred to ITU

\section{Patient 2 - 27 year old female}

No significant past medical history, no regular medication Presented $2^{\text {nd }}$ June:

- Increasing confusion, lethargy and abdominal pain

- $\quad$ Serum sodium $108 \mathrm{mmol} / \mathrm{L}$

- $\quad$ Seizure in ED - intubated and transferred to ITU

\section{Analysis}

\begin{tabular}{|l|c|c|}
\hline & PATIENT 1 & PATIENT 2 \\
\hline Serum sodium (mmol/L) & 123 & 108 \\
\hline Creatinine (umol/L) (eGFR) & 76 & 62 \\
\hline Liver function tests & Normal & Normal \\
\hline Serum glucose mmol/L & Normal & 6.4 \\
\hline Lipids & NA & $\uparrow$ total cholesterol (7) \\
\hline TSH (U/mL) +/- T3/4 & 0.67, fT4 21 pmol/l & 1.9 \\
\hline 9am cortisol (nmol/L) & 480 & 872 \\
\hline Serum osmolarity (mOsm/kg) & 255 & 251 \\
\hline Urine osmolarity (mOsm/kg) & 614 & 582 \\
\hline Urine sodium (mEq/L) & 195 & 194 \\
\hline
\end{tabular}

\begin{tabular}{|c|c|c|}
\hline & PATIENT 1 & PATIENT 2 \\
\hline CXR & Normal & Normal \\
\hline CT/MRI head & CT Head- normal & CT Head- normal \\
\hline Further imaging/investigation & $\begin{array}{l}\text { CT Abdo-pelvis- } \\
\text { Normal }\end{array}$ & $\begin{array}{l}\text { CT CAP- Bulky right } \\
\text { adnexa and small } \\
\text { cyst in the left adnexa }\end{array}$ \\
\hline & PATIENT 1 & PATIENT 2 \\
\hline Urinary porphobilinogen & 1136umol// $(<10.7)$ & $286.2 \mathrm{umol} / \mathrm{l}(<10.7)$ \\
\hline Porphyrin Fractionation & $91 \%$ & $83 \%$ \\
\hline
\end{tabular}

Diagnosis: Acute intermittent porphyria (AIP)

\section{Discussion}

Acute Intermittent Porphyria (AIP) is an autosomal dominant condition that results from a partial deficiency in activity of porphobilinogen deaminase, the third enzyme in the pathway of haem synthesis. The deficiency leads to increased blood levels of porphobilinogen and decreased haem synthesis. Clinical manifestations classically include recurrent unexplained abdominal pain, peripheral neuropathy and neuropsychiatric symptoms.

Hyponatraemia occurs in approximately $20 \%$ of cases of symptomatic AIP and is usually due to SIADH.

Both patients discussed were treated for acute severe hyponatraemia secondary to SIADH, with multiple boluses of $2.7 \%$ hypertonic saline and strict fluid restriction. Extensive imaging in each case failed to identify an underlying cause. The combination of unexplained SIADH, hypertension and abdominal pain raised the possibility of porphyria as a unifying diagnosis. It was no until they were commenced on haem arginate that immediate normalisation of sodium levels occurred.

The cases highlight that whilst a rare cause of hyponatraemia, in unexplained SIADH in young patients with additional symptomatology, a high index of suspicion is needed to accurately diagnose AIP. Early diagnosis, prompt treatment and avoidance of precipitating factors is essential for managing this sometimes fatal condition.

References

-Suarez JI, Cohen ML, Larkin J, Kernich CA, Hricik DE, Daroff RB. Acute intermittent porphyria: clinicopathologic correlation. Report of a case and review of the literature. Neurology. 1997 Jun;48(6):1678-83

-Perlroth MG, Tschudy DP, Marver HS, Berard CW, Zeigel RF, Rechcigl M, Collins A. Acute intermittent porphyria. New morphologic and biochemical findings. Am J Med. 1966 Jul;41(1):149 62.

•Nabin A1, Thapa LJ, Paudel R, Rana PV. Acute intermittent porphyria with SIADH and fluctuating dysautonomia. Kathmandu Univ Med J (KUMJ). 2012 Apr-Jun;10(38):96-9. 